\title{
Analisis Faktor Yang Dipertimbangkan Dalam Penentuan Nisbah Bagi Hasil Pembiayaan Mudharabah Dan Musyarakah Pada PT BANK BNI SYARIAH Cabang Jember
}

\author{
LiaRachmawati $^{1}$, Wiwik Fitria Ningsih ${ }^{2}$ \\ Sekolah Tinggi Ilmu Ekonomi Mandala Jember ${ }^{1,2}$
}

\begin{abstract}
The purpose of this study is to analyze the factors considered in determining the profit sharing ratio of mudharabah and musharaka financing in BNI syariah Ltd. Jember branch. This research uses positivistic paradigm with qualitative approach. Based on the results of the following research several factors into consideration in the determination of the ratio of profit sharing there are The system of sharing based on revenue sharing; Good relationship with customers; Amount of financing value; The business feasibility of the customers; Estimated customer turnover.
\end{abstract}

Keywords: musharaka, nisbah, revenue sharing

\section{Pendahuluan}

Bank syariah sudah beroperasi di Indonesia sejak tahun 1992, yang di mulai dengan beroperasinya Bank Muamalat Indonesia. Bank syariah diatur secara formal sejak diamandemennya UU No 7 Tahun 1992, UU No.23 Tahun 1999 dan di UU nomor 21 tahun 2008. Bank syariah menggunakan sistem bagi hasil, pada sistem ini dana yang diinvestasikan melalui penerapan asas mudharabah dan musyarakah memiliki kemungkinan untung,rugi, atau kembali modal.

Pembiayaan Mudharabah adalah akad kerja sama antara shahibul maal (Pemilik dana) dan mudharib (Pengelola dana) dengan nisbah bagi hasil menurut kesepakatan yang dituangkan dalam kontrak yang terjadi di muka. Pembiayaan musyarakah adalah pembiayaan yang digunakan untuk menyelenggarakan suatu

Corresponding Author:

Email :lia_rachmawati@stie-mandala.ac.id 
usaha tertentu yang dilakukan antara dua pihak atau lebih, masing-masing pihak memberikan kontribusi dana dengan kesepakatan bahwa keuntungan dan risiko akan ditanggung bersama sesuai dengan kesepakatan (Muhammad, 2001;90). Pembiayaan musyarakah diaplikasikan untuk pembiayaan suatu proyek dimana nasabah dan bank sama-sama menyediakan dana untuk membiayai proyek tersebut. Setelah proyek selesai nasabah mengembalikan dana tersebut bersama bagi hasil yang telah disepakati untuk bank syariah.

Teori keuangan mengenai mudharabah dan musyarakah dapat dijelaskan menggunakan teori keagenan atau agency theory, menurut jensen dan meckling (1976) hubungan keagenan sebagai sebuah kontrak antara satu orang atau lebih pemilik modal (principal) yang menyewa orang lain (agent) untuk melakukakan beberapa jasa atas nama pemilik yang meliputi pendelegasian wewenang pengambilan keputusan kepada agen.

Nisbah bagi hasil merupakan faktor penting dalam menentukan besarnya bagi hasil di bank syariah. Nisbah merupakan suatu kesepakatan yang disepakati bersama antara kedua belah pihak yang bertransaksi. Tingkat nisbah bagi hasil sangat mempengaruhi perkembangan bank itu sendiri. Semakin optimal nisbah bagi hasil atau suatu pembiayaan, maka akan semakin banyak nasabah yang dibiayai menjadi lebih giat untuk mengembangkan usahanya dan nasabah tertarik untuk menanamkan modalnya pada bank syariah.

Bank syariah dan bank konvensional mempunyai perbedaan tertentu dalam penentuan suku bunga (bank konvensional) atau bagi hasil (bank syariah) atas satu kredit atau pembiayaan yang akan diberikan. Disamping itu terdapat prosedur dan faktor-faktor tertentu yang harus dipertimbangkan untuk menetapkan besarnya nisbah bagi hasil.

Penelitian ini menggunakan pembiayaan mudharabah dan musyarakah, karena pembiayaan mudharabah dan musyarakah merupakan produk pembiayaan berprinsip bagi hasil yang paling sering dilakukan oleh bank syariah dibandingkan pembiayaan muzara'ah dan musaqah dimana keduanya masih sulit diterapkan karena mempunyai tingkat risiko yang tinggi yaitu dipergunakan khusus untuk pembiayaan pertaniaan atau plantation financing (Muhamad,2011), dalam 
prakteknya membutuhkan kepercayaan dari bank syariah kepada nasabah yang menerima pembiayaan.

Dari uraian di atas dapat menjelaskan bahwa dalam penetapan besarnya nisbah bagi hasil pada pembiayaan mudharabh dan musyarakah di Bank Syariah memerlukan faktor-faktor yang perlu dipertimbangkan, sehingga penulis tertarik untuk melakukan penelitian mengenai "Analisis Faktor-Faktor Yang Di Pertimbangkan Dalam Penentuan Nisbah Bagi Hasil Pembiayaan Mudharabah dan Musyarakah pada PT Bank BNI Syariah Cabang Jember"

\section{METODE PENELITIAN}

\subsection{Rancangan Penelitian}

Penelitian ini menggunakan paradigma positivistik (fakta sosial) dengan pendekatan kualitatif, yaitu paradigma yang menganggap realitas itu sebagai sesuatu yang empiris atau benar - benar nyata dan dapat diobservasi,bertujuan untuk menjelaskan, penyelidikan (ekplorasi), deskripsi, dan juga proses terjadinya. Metode yang dilakukan dengan cara mengumpulkan, memperiapkan serta menganalisis data sehingga mendapat gambaran yang jelas mengenai masalah yang diteliti. Pendekatan kualitatif deskriptif bertujuan untuk mendeskripsikan secara sistematis, faktual dan akurat, mengenai fakta - fakta, sifat - sifat serta hubungan antara fenomena yang diteliti. Paradigma positivistik dengan pendekatan kualitatif yang digunakan lebih menekankan pada penjelasan secara rinci dan mendalam mengenai objek studi serta mempelajari salah satu proses bank syariah mengenai penentuan nisbah beserta faktor yang mempengaruhinya dalam pembiayaan Mudharabah dan Musyarakah.

Pendekatan kualitatif adalah prosedur yang menghasilkan data - data deskriptif yang meliputi kata - kata tertulis atau lisan dari orang - orang yang memahami obyek penelitian yang sedang dilakukanyang dapat didukung dengan studi literatur berdasarkan pendalaman kajian pustaka, baik berupa penelitian, maupun angka yang dapat dipahami dengan baik (Lexy, 2006:6). Pendekatan kualitatif menekankan pada pemahaman mengenai masalah - masalah dalam kehidupan sosial berdasarkan kondisi realistis atau natural setting yang kompleks dan rinci ( Nur Bambang, 2002 ). 
Miles dan Huberman (1984) mengemukakan bahwa aktivitas dalam analisis data. Yaitu pengumpulan data (data Collection), reduki data (data reduction), penyajian data (data display) dan penarikan Kesimpulan (Conclussion). Pendekatan kualitatif yang digunakan lebih menekankan pada penjelasan secara rinci dan mendalam mengenai obyek studi serta mempelajari proses management dan operasional Bank Syariah dan juga menganalisis faktor - faktor yang dipertimbangkan dan juga prosedur dalam penetuan nisbah bagi hasil pembiayaan Mudharabah dan Musyarakah pada Bank BNI Syariah Jember.

\subsection{Unit Analisis}

\subsubsection{Obyek Penelitian}

Obyek penelitian yang digunakan adalah BNI Syariah Cabang Jember yang berlokasi di Jl. A. Yani No 39 Jember

\subsubsection{Informan}

Informan atau Narasumber adalah orang yang dianggap memiliki informasi tentang Obyek yang ingin diteliti. Informan telah ditetapkan kriterinya dengan Purposive Sampling. Purposive Sampling yaitu metode dengan pengambilan data yang terjadi ketika seorang peneliti memilih anggota untuk menyesuaikan diri dengan beberapa kriteria (Danang, 2012:59). Peneliti memilih manager atau penyelia pembiayaan sebagai informan sebagai kriteria yang diajukan yaitu seorang informan yang paham, berwenang, dan juga bertanggung jawab atas segala kegiatan pembiayaan yang terjadi di Bank BNI Syariah Jember.

\subsection{Jenis Dan Sumber Data}

Jenis data penelitian berkaitan dengan sumber data dan pemilihan metode yang digunakan oleh peneliti untuk memperoleh data penelitian (Nur dan Bambang, 2002:146). Jenis data yang digunakan dalam penelitian ini adalah data subyek (Self-report data) dan Data Dokumenter (documentery Data).

a. Data subyek (Self-Report Data)

Berupa opini, sikap, pengalaman atau karakteristik dari seseorang atau sekelompok orang yang menjadi subyek penelitiaan yaitu manager pembiayaan pada bank BNI Syariah.

b. Data Dokumenter (documentery Data) 
Data Dokumenter memuat apa dan kapan suatu kejadian atau transaksi, serta siapa yang terlibat dalam suatu kejadian. Dalam penelitian ini Data Dokumenter berupa laporan atas transaksi pembiayaan mudharabah dan musyarakah yang merupakan data historis dari Bank BNI Syariah Jember.

Penelitian ini menggunakan data primer dan data sekunder. Data primer adalah data yang langsung diberikan kepada pengumpul data. Data primer pada penelitian ini di dapatkan melalui wawancara langsung dengan informan yaitu manager atau penyelia pembiayaan PT Bank BNI Syariah Cabang Jember

Data Sekunder Menurut Nur Dan Bambang (2002) Merupakan Data Penlitian yang diperoleh peneliti dan dicatat oleh pihak lain. Data sekunder dalam penelitian ini diperoleh dari buku - buku dan laporan - laporan tertulis dari PT Bank BNI Syariah Cabang Jember, serta literatur lain yang sesuai dengan tujuan penulisan. Dari data sekunder ini penulis memperoleh catatan yang dianlisis dan dievaluasi bersama dengan data primer.

\subsection{Metode Pengumpulan Data}

Teknik Pengumpulan data dalam penelitian ini meliputi :

a. Observasi

Merupakan teknik pengumpulan data yang digunakan melalui pengamatan dan pencatatan gejala - gejala yang tampak pada obyek penelitian yang pelaksnaannya langsung pada tempat dimana suatu peristiwa, keadaan/situasi sedang terjadi (Hadari,1998:100). Pada tahap ini peneliti melakukan pengamatan mengenai kegiatan operasional bank syariah. Dari pengamatan tersebut peneliti melakukan penelitian yang selanjutnya diperoleh data sebagai bahan analisis yang mendukung penulisan.

b. Wawancara

Dapat dipandang sebagai metode pengumpulan data dengan sistematis dan berlandaskan kepada tujuan penelitian (sutrisno,1980:226). Pihak - pihak yang terkait dalam penelitian ini adalah manager/penyelia pembiayaan pada Bank BNI Syariah Jember.

c. Studi Dokumen

Studi dokumen merupakan teknik pengumpulan data yang tidak ditujukan 
langsung oleh subyek penelitian. Dokumen yang diteliti dapat berbagai macam, tidak hanya dokumen resmi, bisa berupa buku harian, surat pribadi, notulen rapat, laporan, catatan kasus dalam pekerjaan sosial dan dokumen lainnya. Studi dokumen disini yaitu mempelajari dokumen - dokumen yang berhubungan dengan pembiayaan mudharabah dan Musyarakah yang ada pada Bank BNI Syariah Jember.

\subsection{Validitas Data}

Validitas data dalam penelitian kualitatif mengacu pada apakah temuan penelitian secara akurat mencerminkan situasi dan didukung oleh bukti.

Miles Huberman (1984) menyataka bahwa pemeriksaan konistensi temuan yang dihasilkan oleh metode pengumpulan data yang berbeda seperti melengkapi data wawancara dengan data observasi. Hasil survei, data wawancara dan observasi dapat dibandingkan untuk melihat apakah hasil temuan sama, jika kesimpulan dari masing - masing metode sama maka penelitian tersebut valid. Penelitian ini menggunakan triangulasi data yaitu dengan cara menggunakan dua metode pengumpulan data yaitu observasi, wawancara dan studi dokumen untuk menjaga kevalidan data.

\subsection{Metode Analisis Data}

Teknik analisis yang digunakan adalah analisis deskriptif kualitatif. Hasil deskripsi pada tahapan pengolahan data dibandingkan dengan landasan teori. Dari hasil analisis tersebut akan ditarik suatu kesimpulan dan akan dikemukakan saran saran dan perbaikan jika diperlukan.

\section{PEMBAHASAN}

BNI Syariah didirikan dengan memanfaatkan jaringan BNI Konvensional yang ada baik fasilitas ATM maupun kantor cabang BNI konvensional dengan melalui syariah production counter. Dengan demikian layanan syuariah ini selain di cabang syuariah yang bersangkutan juga dapat dilayani di kantor cabang konvensional transaksi pembukuan rekening tabungan dan deposito.

Landasan hukum yang mendasari berdirinya PT. BNI Syariah KC Jember adalah Undang-undang nomor 7 tahun 1992 tentang perbankan dan Undang-undang Nomor 21 tahun 2008 tentang perbankan syariah. 
BNI Syariah menawarkan dua produk yaitu produk pendanaan dan produk pembiayaan. Jenis produk pendanaan diantaranya sebagai berikut; 1. BNI Baitullah iB Hasanah adalah tabungan dengan akad Mudharabah atau Wadiah yang dipergunakan sebagai sarana untuk mendapatkan kepastian porsi berangkat menunaikan ibadah Haji (Reguler/Khusus) dan merencanakan ibadah Umrah sesuai keinginan penabung dengan sistem setoran bebas atau bulanan dalam mata uang Rupiah dan USD dan masih banyak lagi produk pendanaan lainnya; 2.BNI Deposito iB Hasanah yaitu investasi berjangka yang dikelola berdasarkan prinsip syariah yang ditujukan bagi nasabah perorangan dan perusahaan, dengan menggunakan akad mudharabah. Fasilitas: Bilyet Deposito Terdapat pilihan mata uang Rupiah dan US Dollar Terdapat pilihan jangka waktu : 1,3,6,12 bulan Manfaat : Dapat atas nama perorangan maupun perusahaan; 3.. BNI Giro iB Hasanah adalah simpanan transaksional dalam mata uang IDR dan USD yang dikelola berdasarkan prinsip syariah dengan pilihan akad Mudharabah Mutlaqah atau Wadiah Yadh Dhamanah yang penarikannya dapat dilakukan setiap saat dengan menggunakan Cek, Bilyet Giro, Sarana Perintah pembayaran lainnya atau dengan Pemindahbukuan; 4. bni dolar IB Hasanah yaitu Tabungan yang dikelola dengan akad wadiah dan mudharabah yang memberikan berbagai fasilitas serta kemudahan bagi Nasabah Perorangan dan Non Perorangan dalam mata uang USD; 5. BNI simple ib hasanah yaitu Tabungan dengan akad wadiah untuk siswa berusia di bawah 17 tahun dengan persyaratan mudah dan sederhana serta fitur yang menarik untuk mendorong budaya menabung sejak dini. Sedangkan untuk jenis produk pembiayaan diantaranya terdapat produk pembiayaan dengan menggunakan prinsip jual beli yaitu menggunakan akad murabahah seperti Multiguna iB Hasanah; Oto iB Hasanah; Pembiayaan Emas iB Hasanah; CCF iB Hasanah; Fleksi iB Hasanah Umrohdan BNI Syariah KPR Syariah;2. produk pembiayaan dengan menggunakan prinsip bagi hasil yaitu menggunakan akad musyarakah seperti Wirausaha iB Hasanah (WUS), Tunas Usaha iB Hasanah,Usaha Kecil iB Hasanah.

Prinsip bagi hasil secara umum dalam perbankan syariah dapat dilakukan dalam empat akad utama. Yakni, musyarakah, mudharabah, muzara'ah, dan musaqah. 
Dari empat akad tersebut bni syariah jember hanya menggunakan satu akad, yakni akad musyarakah. Musyarakah adalah penempatan dana dari pemilik dana / modal untuk menggabungkan dana / modal usaha tertentu, dengan pembagian keuntungan berdasarkan rasio yang disepakati sebelumnya, sedangkan kerugian ditanggung oleh seluruh pemilik dana / modal berdasarkan Bagian dana / modal masing-masing.

Dari hasil penelitian yang dilakukan ditemukan bahwa faktor faktor yang dipertimbangkan dalam penentuan nisbah bagi hasil pembiayaan musyarakah pada PT Bank BNI Syariah cabang Jember antara lain

1. Sistem bagi hasil berdasarkan revenue sharing

Dlam pembagian hasil usaha sistem yang digunakan berdasarkan revenue sharing bukan profit sharing. revenue sharingberarti proses bagi pendapatan yang dilakukan sebelum memperhitungkan biaya-biaya operasional yang ditanggung oleh bank, biasanya pendapatan yang didistribusikan hanyalah pendapatan atas investasi dana, dana tidak termasuk fee atau komisi atau jasa-jasa yang diberikan oleh bank karena pendapatan tersebut pertama harus dialokasikan untuk mendukung biaya perasional bank. Dilihat dari segi kemaslahatannya (al-ashlah), pembagian hasil usaha sebaiknya digunakan prinsip bagi hasil (revenue sharing). Karena pada prinsip sistem profit sharing yang di dalam penerapannya banyak kendala, diantaranya adalah sulitnya pengakuan atau estimasi biaya yang dikeluarkan dalam usaha, serta rumitnya pola pembagiannya pada prinsip perbankan modern (budiawan, 2013).

2. Hubungan baik dengan nasabah

Nasabah lama lebih dipertimbangkan daripada nasabah baru. Pada nasabah baru, besaran nisbah yang menentukan adalah pihak Bank. Sebagaimana yang dinyatakan oleh ikatan bankir indonesia,2014 bahwa bank harus mengenal terlebih dahulu calon debiturnya, terutama karakternya. Kajian mengenai karakter dapat dilakukan dengan cara Bank Checking melalui sistem informasi debitur / SID pada Bank Indonesia. Semakin dekat hubungan antara pihak bank dan nasabah maka bisa jadi nisbah bagi hasil 
kedua belah pihak tidak terlalu terikat atas faktor-faktor yang lain, asalkan usaha yang dijalankan menjamin adanya keuntungan (Gayuh, 2011; yudhawirawan, 2006)

3. Jumlah nilai pembiayaan

Pada BNI Syariah cabang jember yang menjadi salah satu faktor yang dipertimbangkan dalam nisbah bagi hasil dalam pembiayaan dengan akad musyarakah adalah besarnya nilai nominal pembiayaan. Nisbah dapat berbeda antara satu nasabah dengan nasabah lainnya sesuai dengan besarnya dana dan jatuh temponya (muhammad, 2001; ika, 2010; gayuh, 2011). Dalam hal ini dapat diartikan bahwa semakin besar nilai semakin besar untuk melakukan negosiasi nisbah.

4. Kelayakan usaha yang dijalankan nasabah Kelayakan usaha yang dijalankan nasabah juga diperhatikan untuk memutuskan besaran nisbah calon nasabah.pihak bank akan melakukan analisis untuk mengetahui apakah calon nasabah memiliki tingkat kelayakan pembiayaan atau tidak. faktor-faktor yang dipertimbangkan dalam penentuan nisbah bagi hasil atas pembiayaan musyarakah adalah kebutuhan riil modal kerja, kontribusi modal (dana) bank, proyeksi keuntungan usaha nasabah, omzet usaha nasabah, cash flow usaha nasabah, jangka waktu pembiayaan musyarakah, prospek usaha yang akan dijalankan nasabah (Wulandari, 2010).

5. Perkiraan omset nasabah

Perkiraan omset nasabah digunakan sebagai salah satu faktor dalam menentukan nisbah pada nasabah BNI Syariah cabang Jember. Jumlah pembagian laba meningkat sesuai dengan peningkatan jumlah pedapatan (muhammad, 2004). Semakin besar omzet usaha nasabah maka semakin kecil nisbah untuk bank dan sebaliknya (Yudhawirawan, 2006). Dengan demikian nisbah berdasarkan omzet dari usaha nasabah sesuai dengan laporan keuangan nasabah. 


\section{KESIMPULAN}

Berdasarkan hasil penelitian yang dilakukan pada bank BNI Syariah Cabang Jember beberapa faktor yang menjadi pertimbangan dalam penentuan nisbah bagi hasil diantaranya 1 . Sistem bagi hasil berdasarkan revenue sharing; 2 . Hubungan baik dengan nasabah; 3.Jumlah nilai pembiayaan; 4. Kelayakan usaha yang dijalankan nasabah; 5.Perkiraan omset nasabah.

Penelitian selanjutnya sebaiknya menggunakan objek berupa BPRS untuk pengembangan penelitian.

\section{DAFTAR PUSTAKA}

Abdul Ghofur Anshori. (2007). Perbankan Syariah di Indonesia. Yogyakarta: Gadjah Mada University Press

Agustianto. (2010). Penentuan Bagi Hasil Deposito Mudharabah di Bank Syariah Gita Danuprata. (2013). Buku Ajar Manajemen Perbankan Syariah. Jakarta : Salemba Empat

Ika Rulita Herlinayanti. (2010). Faktor-faktor yang dipertimbangkan dalam penentuan nisbah bagi hasil atas pembiayaan, mudharabah pada PT Bank Syariah Mandiri pada PT Bank Syariah Mandiri dan Bank Muamalat cabang Jember.

Jensen, M. And Meckling, W., (1976). Theory of the Firm: Managerial Behavior Agency Cost and Ownership Structure, Journal of Finance Economics 3,pp 305-360.

Muhamad. (2004). Tehnik Perhitungan Bagi Hasil dan Pricing Pada Bank Syariah. Yogyakarta: UII Pers

Muhamad. (2005),Kontruksi Mudharabah Dalam Bisnis Syaria'ah Mudharabah Dalam Wacana Fiqih dan Praktik Ekonomi Modern. Yogyakarta : BPFE-Yogyakarta.

Muhammad. ( 2014). Manajemen Dana Bank Syariah. Jakarta PT Raja Grafindo Persada

Muhammad Syafi'i Antonio. (2001). Bank Syariah dari Teori ke Praktik. Jakarta Gema Insani Press. 
Jurnal Relasi, Vol. XIV, No. 02, Juli 2018

Yaninsa Dwi Wulandari, 040630939 (2009). Analisis Faktor-Faktor Yang Dipertimbangkan Dalam Penentuan Nisbah Bagi Hasil Atau Pembiayaan Mudharabah Dan Musyarakah Pada BANK SYARIAH. Skripsi thesis, UNIVERSITAS AIRLANGGA.

http://www.bnisyariah.co.id/ 